\title{
The Practice and Problems of UAVs Regulation and Legislation in Local China from the Perspective of Public Safety
}

\author{
Jiuyang Yao \\ Shanghai University of Political Science and Law, Shanghai, China \\ Email:958324049@qq.com
}

How to cite this paper: Yao, J. Y. (2021). The Practice and Problems of UAVs Regulation and Legislation in Local China from the Perspective of Public Safety. Open Journal of Social Sciences, 9, 54-64. https://doi.org/10.4236/jss.2021.94006

Received: March 12, 2021

Accepted: April 9, 2021

Published: April 12, 2021

Copyright $\odot 2021$ by author(s) and Scientific Research Publishing Inc. This work is licensed under the Creative Commons Attribution International License (CC BY 4.0).

http://creativecommons.org/licenses/by/4.0/

\section{(c) (i) Open Access}

\begin{abstract}
UAVs are spreading rapidly, but how to prevent their potential public safety hazards has become a common problem of public safety management for governments around the world. From "blocking" to "relieving", local governments in China have gradually come up with clear ideas on how to regulate in the form of legislative practice. Although there are still some problems with leniency and strictness, the government serves as a leading role in promoting the legislative process of a comprehensive drone safety law to protect public safety. This paper intends to provide some reference for solving the problem of UAV supervision by combing the practice of local UAV in legislation and supervision in some areas of our country.
\end{abstract}

\section{Keywords}

Drones, UAV Safety Law, Public Safety

\section{Introduction}

Maintaining social stability and order and protecting citizens' lives and properties from infringement are the primary tasks of the local governments. Due to the characteristics of civilian drone technology and applications, the potential public safety risks are increasingly causing concerns among people and governments. In China, a drone interfered airport flights at Chengdu Shuangliu Airport in 2017, which pushed UAV public safety concerns to the forefront and prompted localities to focus on drone flights as an important regulatory target. Soon afterwards, Sichuan, Guangdong, Chongqing, Zhengzhou, Shenzhen, Xinjiang Uygur Autonomous region, Shanghai and other places successively issued a series of local policies on UAV supervision, for example, the Sichuan Provincial interim 
regulations on Safety Management of Civil Unmanned aerial vehicles issued in August 2017. In addition, the Sichuan Provincial rules for Cooperative Management of low-altitude airspace (interim) issued in December 2018 stipulate the real name registration of civil UAV owners, users obtaining driving licenses and low-altitude airspace flight management and other system contents. Moreover, in May 2020, the Shanghai Municipal Public Security Bureau and other nine departments jointly issued notices to strengthen the safety management of civil drones and other "low-slow and small" aircraft in the city. As the "test fields" to promote the development of UAV, these provinces and cities provide practical experience for the legal regulation of public safety of UAV in our country. In addition, there are temporary documents to regulate the flight of drones. For example, the Circular of the Beijing Municipal Public Security Bureau on strengthening the management of "low, slow and small" aircraft in the Beijing area during the 2019 National "two sessions" issued by Beijing during the two sessions stipulates that during the two sessions, all recreational UAV aircrafts are not allowed to fly within the administrative area of Beijing. The control of civil UAV has played a certain effect though such regulations have been issued one after another. However, the phenomenon affecting public safety is still repeatedly banned. From the perspective of public safety, these regulatory policies and legislative initiatives are still in their infancy, and regulatory measures are still facing dilemmas in implementation. Their scientificity and effectiveness are also controversial. Therefore, analyzing the problems of UAV regulation in various places and their regulatory measures can provide useful experience and reference for the legislation and practice of UAV safety regulation in China.

The hidden danger of public safety caused by UAV flight has become increasingly prominent with the continuous expansion of the application field. More and more domestic researchers begin to pay attention to UAV. In addition, the research on the legal regulation of its public safety is gradually on the rise. First, it is about drones and public safety. According to the article "Research on the potential threat and Security Control of Civil UAV to National Security" (Liang, 2018), drones pose a potential threat to national political security, homeland security, military security and social security. Among them, the threats posed by drones to social security include: On the one hand, interfere with the safe flight of civil aircraft. The flight of UAV near the airport may affect the normal take-off and landing of flights and disrupt the normal operation of the airport; It will seriously lead to flight accidents if the UAV collides with the aircraft. On the other hand, accidental crash of drones will endanger the personal and property safety of citizens. At present, there have been a number of accidents caused by the crash of drones in China. There is also a situation of using drones to transport express delivery with the continuous improvement of UAV technology. It is considered that the improvement of UAV flight height, load and range capability has brought greater security risks in addition to the threat to airspace and ground security. It is very likely to be used by lawbreakers to carry out criminal 
activities such as smuggling and drug trafficking. Secondly, the legislation and regulation of drones. The article "how to manage UAV" holds that the regulations on the production and use of UAV in our country are more principled and general, and the legislation on many issues is still in a blank state in the aspect of legislation (Yang \& Cheng 2017). The article "Research on the legal regulation of civil UAV in China from the perspective of scientific and technological administrative law" holds that the problems existing in the legal regulation of UAV are as follows: the legislative level of the normative documents formulated by the Civil Aviation Administration is not high. In addition, some provisions are lack of maneuverability. There is no omni-directional and systematic legal regulation (Yang, 2018).

In addition, "the safety risks and control strategies brought about by the wide application of light and micro UAV" proposed that the relevant normative documents of UAV are only temporary and instructive for different types of UAV legislation (Huang \& Xiong, 2015). A complete and targeted regulation system for civil light and micro UAV has not been formed. The article "discussion on the basic issues of legal regulation of civil UAV" holds that there will be regulatory confusion in the large number of regulatory subjects of UAV at present in terms of regulation. The article "Research on the Supervision system of Civil UAV in China" points out that the lack of appropriate access system in the UAV industry leads to the disunity of UAV production quality and technical standards; There is basically no relevant legal regulation in addition to export restrictions. The commercial and entertainment uses of UAV are more popular in foreign countries (Gao, 2017). As a consequence, the research of foreign researchers on UAV is mainly focused on the protection of privacy, personal information and data security and so on. Clarke Roger, Bennett Moses, Lyria and others believe that even normal operation of drones in the air may pose a threat to people and objects on the ground, let alone when the data communications they rely on fail with regard to the regulation of drones. Moreover, the remedial measures provided by the general tort liability law for the damage caused by drones cannot prevent the flight behavior of irresponsible drone users. The government should establish a common regulatory mechanism to incorporate the self-regulation of industries and organizations into the regulatory system, especially to strengthen the supervision of small drones (Clarke \& Moses, 2014). Rao Bharat, Gopi Ashwin Goutham, Maione Romana and others believe that the application of UAV brings challenges to security, law and regulation with the development of UAV technology. To this end, they propose that drones should not only be used for private entertainment, but also be integrated into the existing public domain and government infrastructure (Rao et al., 2016). Hiroko Nakamura, Yuya Kajikawa focused on the legislation and regulation of small drones. They were tightly regulated by the government and revised Japan's civil aviation law as a result of the 2015 incident at the prime minister's official residence. The author also puts forward an alternative method of stakeholder regulation. In 
other words, it achieves the supervision of small UAV through cooperation with operators and manufacturers (Nakamura \& Kajikawa, 2018). Mathews, Benjamin $\mathrm{D}$ believed that there is a conflict between the right of private use of drones and the protection of personal rights. It may lead to potential tort liability. As a consequence, he discussed the legal application of federal regulations and tort laws to the management of drones (Mathews, 2015).

Domestic researchers tend to discuss the legal regulation of public safety of UAV from the perspective of supervision from the current research situation at home and abroad. However, foreign researchers pay more attention to the exploration of UAV flight infringing on civil rights. It provides a useful reference for the legislation of local UAV supervision in China. Generally speaking, as a new thing in China, UAV has been widely used in various fields. However, the research on how to regulate the public safety of UAV still needs to be further studied.

\section{UAV Regulation and Legislation-Common Challenges}

The regulation of drones is one of the global concerns. At the same time, the difficulty of legislation and regulation is a common problem faced by countries around the world.

First, UAV is a brand-new technology of aviation and wireless control, which has went beyond of the traditional aviation regulatory system and is a brand new regulatory field of public safety. For many years, the traditional aviation control prevailing around the world has been very well developed and become an effective regulatory system. For example, the aviation industry has established a complete standard system for aircraft airworthiness, airspace delineation, airport setup, route planning, position navigation, pilot training, etc. Modern UAVs integrate modern avionics, wireless communication technology, sensor and positioning technology and intelligent control technology. They have significant differences from traditional aircraft in terms of appearance and size, flight control and flight characteristics. Over the years, the prevailing national aviation control technology, experience and system based on existing civil aviation technology has not been able to adapt to the changes brought about by the development of this new technology, and still significantly lags behind.

Second, compared with traditional flying machines, modern UAVs enjoys broader application. Due to the flexible flight routes and low cost of drones, they have become a real cross-border tool from the earliest military battlefield to police patrol, film and television shooting, rescue and disaster relief, agriculture and forestry vegetation, meteorological investigation, geological exploration, power detection, express, E-sports and other industries. At the same time, drones are easy to operate and do not require training to get started. Therefore, in addition to many institutions, there are also many individual users, whose flights are more diverse. The traditional point-, machine- and person-fixed regulation is unable to cope with the numerous drone flights in terms of human and material 
resources.

Third, as an emerging cross-border tool, the regulatory legislation of drones involves various aspects. Public safety is the primary consideration for regulation. But it also involves other issues such as technological innovation, industrial development, people's rights and social ethics. The United States, for example, is a leader in the development and application of modern drone technology. As early as the 1990s, modern drone technology has sparked social concern and legislative consideration. With the signing of the FAA Modernization and Reform Act of 2012, there is a rapid rise of civilian drone applications. New discussions also arise from the public: the threat of civilian drones to public safety and personal privacy, the integration and conflict between the traditional aviation regulatory system and drone technology, the contradiction between public safety and constitutional civil rights protection and between strengthening regulation and promoting technological development, and the specific regulatory initiatives of the FAA and so on. Because of the multiple interests involved in drone regulation, the Federal Aviation Administration (FAA), as the competent agency, is still struggling and exploring (Scott, 2016).

Fourth, two outstanding problems still face UAV regulation in China. The first one is the lack of relevant regulations, with legislation lagging behind. Drone regulations lack a perfect and highly effective "parent" law. Drone legislation should have been supported by the higher-ranking "Civil Aviation Law" and the second-ranking "General Aviation Law", but in reality, China's general aviation-related regulations are missing or fragmented. The most effective "Civil Aviation Law" has been promulgated for many years and has been revised, it is still not perfect enough because there lots of loopholes. Thus the existing industry regulations can not provide direct and effective support. Second, the domestic regulation of drones also needs to be combined with the development of the drone industry, and to strike a balance between public safety and technological innovation. China is a large country of drones, with the research and application ranking among the world's top. As a representative of technological innovation and intelligent production, China urgently needs a good regulatory system for the healthy development and application of the UAV industry. The lack of drone regulations and improper regulatory measures will inevitably lay a negative impact on China's drone industry.

In conclusion, the dilemma and pressure on making and implementing drone regulation policies around the world is evident due to the urgent need of ensuring public safety.

\section{From "Blocking" to "Relieving": Local Authorities' Regulatory Development}

The disorderly flight of drones and the long lack of supervision are bound to bring huge potential dangers to public safety. To ensure public safety, it should be the responsibility of governments around the world to safeguard peace and 
security by regulating all kinds of drones and actively exploring and improving effective methods for drone regulation. In recent years, governments and management agencies have made some attempts, which gradually reflected the policy transition from "banning" to scientific "guiding". From the perspective of public safety, restricting or even banning drone activity is the most straightforward approach. In fact, among the early practices of drone regulation around the world, banning is the most common. It should be seen that during important party and government meetings, state events or public celebrations, the temporary banning of drones is an effective and reasonable method. However, if this idea is still followed in daily management, it will inevitably suppress the innovation and application of new drone technology and violate people's right to use new technology. The result will instead lead to more disorderly flights, increased safety hazards and increased public concern. The scientific strategy should be a combination of leniency and strictness, ban and release. That is to seek for a reasonable balance between public safety and the application of drone technology. In recent years, the management measures reflect a common progress mainly from the following aspects.

First, emphasize the responsibilities and qualifications of drone users, and clarify the basic requirements like real-name registration of drones, pilot qualification and flight plan filing. At present, the Civil Aviation Administration of China (CAAC) has issued relevant documents such as "Interim Regulations on the Management of Civil Unmanned Aerial Vehicle System Pilots", "Regulations on the Operation of Small and Light Unmanned Aerial Vehicles (for Trial Implementation)", "Regulations on the Administration of Real-Name Registration of Civil Unmanned Aerial Vehicles", and "Measures for the Administration of Operational Flights of Civil Unmanned Aerial Vehicles (for Interim Implementation)". Some provisions have been clarified and highlighted from the perspective of public safety management. For example, in August 2017, the Sichuan Provincial Government issued the "Interim Provisions on the Safety Management of Civil Unmanned Aerial Vehicles in Sichuan Province". It reiterated that "the owner of a UAV shall register its name, valid document number, contact information, the model, serial number, and purpose of use in accordance with the provisions of the civil aviation department; the institutions shall register the name and the unified social credit code or "organization code"; "civilian drone operators shall obtain pilot qualifications and licenses corresponding to flights in accordance with the law"; "civilian drone flying in controlled airspace shall apply to the flight control department for airspace and flight plans in accordance with the law, and flights shall get approval." The Shenzhen Municipal People's Government issued the "Interim Measures for the Management of Civil Microlight Drones in Shenzhen" in February 2019. Likewise it emphasizes that "the group standard for light drones should achieve real-name registration, coordinate positioning, electronic fencing, platform access and other technical functions to meet the basic functional requirements of the comprehensive supervision platform for 
drone flights." In June 2020, the Shanghai Municipal Public Security Bureau and other nine departments jointly issued a notice to strengthen the safety management of the city's civilian drones and other "low, slow and small" aircrafts: "in accordance with the relevant provisions of civil aviation management, civilian drone owners should be registered in real names, and should obtain the appropriate flight qualification in accordance with the law, and comply with radio management, general aviation flight application management, management of business activities and other relevant provisions before beginning flights in the city's administrative areas.

Second, highlight public safety protection and set no-fly zone for drones. In September 2016, the Western Warzone Air Force Staff Department, the Civil Aviation Southwest Regional Administration, the Civil Aviation Southwest Regional Air Traffic Management Bureau, and the Sichuan Provincial Public Security Department issued the "Notice on Strengthening the Safety Protection of the Province's Military and Civil Aviation Airport Clearance Area", which states, "It is strictly prohibited for any unit or organization and individual to...... carry out flying activities such as drones, model aviation, without the approval of the military and civil aviation departments". This is an early introduction of banning drone flights to protect specific areas in China.

Considering the current regulatory dilemma s and the lack of management, it is a practical and effective choice to ensure public safety by maximizing the protection of public safety and implementing a no-fly control of drones in key areas of public safety. Among the newly introduced local regulatory measures around the world, the setting of no-fly zones is always an important element.

The regulation in Sichuan Province listed above clearly delineates the civilian airports, military management areas, prisons, power plants, railroads and highways, ultra-high voltage transmission lines, large military industries, communication stations, hazardous chemical production and storage areas, material storage areas and other key areas as no-fly areas. Without approval, civilian drones are prohibited from flying over these areas. And in September 2017, the Shenzhen Municipal People's Government issued the "Shenzhen Municipal Civil Light Unmanned Aerial Vehicle Management Measures (Draft for Public Comments)", in which the no-fly areas of drones are divided more comprehensively. It adds urban party committees and governments, military control zones, large event sites, transportation hubs, railway stations, passenger terminals, ports, etc. as no-fly areas for drones that are not approved. And the following provisional draft released in February 2019 keeps the same.

Setting up regular no-fly zones for drones in key areas of public safety is not only necessary but also feasible. It can minimize the public safety risks associated with all types of drone activity. This is the most feasible and effective way to regulate drones.

Third, we need a combination of leniency and strictness, and to manage by classification so that UAV flight demand can be effectively met. Unlike tradi- 
tional aerial vehicles, UAV technology is fast developing, diverse, widely used and has many users. Therefore, we cannot simply apply the existing traditional aviation supervision methods to it. Rather, we should carry out detailed management according to different drones, different applications and different users considering the characteristics of drone applications.

The small and light civilian drone users are most concerned about the pilot qualification and license issues, followed by the flight declaration and approval issues. In Sichuan Province, there is a special explanation on the rules of the pilot qualifications and licenses: "pilot license is not needed for the civilian drone of which the empty weight is less than or equal to $4 \mathrm{~kg}$, or takeoff weight less than or equal to $7 \mathrm{~kg}$ ". Meanwhile, the airspace is categorized and managed, divided into controlled airspace, preparation airspace and self-flying airspace. The civilian drone flights in the preparation airspace and self-flying airspace "do not require flight airspace and flight plan approval". Shenzhen's regulations are specifically made for civilian light unmanned aerial vehicles, with "the takeoff weight more than or equal to $0.25 \mathrm{~kg}$, less than $7 \mathrm{~kg}$, and engaging in non-military, police or customs' anti-smuggling missions". And general flights do not need flight declaration. It tailors for the drones specific no-fly zones and restricted flight areas.

With these scientific and humane regulations, the regulatory pressure can be greatly reduced. Thus the limited regulatory force can be diverted to medium and large drones. Moreover, these regulations can help effectively manage the flights of light and small drones, striking a balance between public safety and protecting people's rights to drone flights.

Fourth, specify drone flight regulations, expand the management scope, and fulfill regulatory responsibilities. Standardized flight control is the premise of reducing flight risks. For the flights of small and light drones, Sichuan Province requires obedience to the airspace management. Among them, the self-flying airspace flight should be operated within the driver's vision. Shenzhen's regulations are more specific: the flight radius of the daytime visual range does not exceed 500 meters, and the relative ground height does not exceed 120 meters. The refinement will help the flyer to self-control and reduce the risk of blind flight. In addition, the safety of drone flights is closely related to the aircraft itself. Sichuan and Shenzhen have required drone producers be regulated and have made concrete provisions for them. Shenzhen requires drone manufacturers to comply with technical specifications, such as activation of certification, satellite positioning, automatic return, electronic fencing, flight records, and access to management platforms. Sichuan Province requires that manufacturers should install flight control chips on civilian drones in accordance with national regulations, set up no-fly zone software, and take technical measures to prevent modifications or changes in settings.

In addition, the two regions have also clarified the division of labour and cooperation of the management departments in the management regulations. For 
example, the government has established a unified leadership and a classified linkage mechanism: the public security authorities are responsible for investigating and dealing with illegal flights; the economic and information technology departments are responsible for managing drone producers and their products; the industry and commerce departments are responsible for the registration of drone producers; the safety supervision departments will incorporate the safety management of civilian drones into the comprehensive target assessment of safety production; the customs are responsible for the supervision of imported civilian drones in accordance with the law; the associations are responsible for self-regulation; drone associations are responsible for self-regulation and guidance, etc. A regulatory blueprint for cooperations among departments and supervisions by the whole society has been initially drawn up.

First, some regions still treat all kinds of drone flying activities without any classification, and the scale of regulation of micro and small drones is too strict to carry out. In Zhengzhou, for example, according to the "Notification on Strengthening the Safety Management of 'low, Slow and Small' Aircraft Flights" issued by Zhengzhou Municipal People's Government in June 2017, “If an institution or individual needs to operate 'low, slow and small' aircraft flights, one needs to report to the military air control department for approval. The approved aircraft must fly in strict accordance with the approved time and area; without approval, all 'low, slow and small' aircraft are strictly prohibited from flying."

As mentioned earlier, there are many types of drones, among which "low, slow and small" drones have limited weight and their safety risks can be controlled. If they should always be reported regardless of area in daily management, it will certainly result in a huge waste of regulatory power. Moreover, "low, slow and small" drones have the largest number of users, and their flights are so flexible and changeable that the existing regulatory mechanism is unable to cope with them. Thus the so-called reporting regulation will ultimately be useless. In contrast, it would be more feasible to classify drones according to their types, characteristics and functions with different levels of regulatory strictness.

Take the United States, where the flight control system is well developed, as an example. Concerned about public safety, the US Aviation Administration has been trying to integrate drones into the traditional air traffic control system and tightening control on them. In practice, however, this has been difficult due to public opinions. Its newly introduced drone registration system has also been in trouble due to individual users suing it as against the constitution. In reality, the US Aviation Administration can only regulate commercial applications of drones; while personal flights of micro and small drones are largely unregulated. The strict local regulation of civilian drones fundamentally stems from the limited opening of China's current low-altitude airspace. The State Council and the Central Military Commission issued the "Instructions on Deepening the Reform of Low Altitude Airspace Management" in 2010, and the General Office of the 
State Council issued the "Instructions on Promoting the Development of the General Aviation Industry" in 2016. Low-altitude airspace is gradually being opened up for classified and managed drones, and the micro and small drones' flight regulations are relaxed. This is not only beneficial to public safety, but also helps the development of the drone industry.

Second, the various regulations governing drones in different places are still too simple regarding to the complex and widespread use of drones. In practice, there is still a need for further refinement of regulations and enforceable standards. Otherwise, there will still be various loopholes and ambiguities in the regulatory practice, which may trigger public safety hazards.

\section{Conclusion}

From the perspective of legislative process of drone regulation, the introduction of drone regulations has been groundbreaking as it has filled the regulatory gap when national laws and industry regulations are still incomplete. However, comparing relevant regulations in different places, we can see that the problems are also apparent.

In fact, a more advanced and more effective drone safety law is needed to ensure that social drone regulation is in place. From a public safety perspective, a drone safety law should place the protection of public safety at its core and thus integrate and refine the various aspects and specific requirements of drone safety. For example, the division of airspace for drones, rules on the use of airspace, flight rules for drones, production technology standards, owner certification, pilot qualification assessment, etc. Considering the rapid development of drone technology, the weakness of the relevant legal basis, the complexity of opening airspace and reconstructing the air traffic control mechanism, the drafting and implementation of drone safety laws will be a long-term process, which requires the joint efforts and participation of the whole society. Thus the current efforts made by local governments and regulatory authorities in formulating regulations on drone management serve as a pioneering role.

\section{Fund}

This article is supported by the Shanghai Law School's University-level Youth Research Project Fund in 2018.

\section{Conflicts of Interest}

The author declares no conflicts of interest regarding the publication of this paper.

\section{References}

Clarke R, \& Moses, L. B. (2014). The Regulation of Civilian Drones' Impacts on Public Safety. Computer Law \& Security Review, 30, 263-285.

https://doi.org/10.1016/j.clsr.2014.03.007 
Gao, G. Z. (2017). Research on Supervision System of Civil UAV in China. Journal of Beijing University of Aeronautics and Astronautics (Social Science Edition), 30, 28-36.

Huang, Z. M., \& Xiong W. H. (2015). Safety Hidden Danger Caused by Wide Application of Light and Micro UAV and Its Management and Control Strategy. Journal of Hebei Public Security Police Vocational College, 15, 32-38.

Liang, H. X. (2018). Research on Potential Threat and Security Control of Civil UAV to National Security. Journal of Jiangnan University of Social Sciences, 20, 31-35.

Mathews, B. D. (2015). Potential Tort Liability for Personal Use of Drone Aircraft. Social Science Electronic Publishing, 47, 573.

Nakamura, H., \& Kajikawa, Y. (2018). Regulation and Innovation: How Should Small Unmanned Aerial Vehicles Be Regulated? Technological Forecasting and Social Change, 128, 262-274. https://doi.org/10.1016/j.techfore.2017.06.015

Rao, B., Gopi, A. G., \& Maione, R. (2016). The Societal Impact of Commercial Drones. Technology in Society, 45, 83-90. https://doi.org/10.1016/j.techsoc.2016.02.009

Scott, B. I. (2016). The Law of Unmanned Aircraft Systems: An Introduction to the Current and Future Regulation under National, Regional and International Law (Aviation Law and Policy). Alphen aan den Rijn: Kluwer Law International.

Yang, L. J. (2018). Research on the Legal Regulation of Civilian Drones in China From the Perspective of Science and Technology Administrative Law. Science and Technology Management Research, 17, 48-53.

Yang, W. M., \& Cheng, H. (2017). Drone, How to Manage. Zhejiang National People's Congress, No. 6, 59-61. 